\title{
Plantas alimentícias não convencionais: existem potenciais consumidores e locais
}

\section{para comprar?}

\author{
Non-conventional food plants: are there potential consumers and places to buy them? \\ Plantas alimenticias no comvencionales: ¿existen posibles consumidores y sitios para comprar?
}

Recebido: 22/03/2021 | Revisado: 29/03/2021 | Aceito: 31/03/2021 | Publicado: 10/04/2021

Tadeu Patêlo Barbosa

ORCID: https://orcid.org/0000-0002-7688-6093 Instituto Federal de Educação, Ciência e Tecnologia de Alagoas, Brasil

E-mail: tadeupbarbosa@gmail.com

Jadson Adyel Santos Lins

ORCID: https://orcid.org/0000-0002-2648-9284 Universidade Federal de Alagoas, Brasil

E-mail: jadsonlins.g3@gmail.com

Geane Maria da silva

ORCID: https://orcid.org/0000-0001-5094-0816 Instituto Federal de Educação, Ciência e Tecnologia de Alagoas, Brasil

E-mail: geaneifal@gmail.com

Ellen Carine Neves Valente

ORCID: https://orcid.org/0000-0002-3839-4856

Universidade Federal de Alagoas, Brasil

E-mail: ellencvalente@yahoo.com.br

André Suêldo Tavares de Lima

ORCID: https://orcid.org/0000-0003-4687-0645

Instituto Federal de Educação, Ciência e Tecnologia de Alagoas, Brasil

E-mail: andre.sueldo@ifal.edu.br

\begin{abstract}
Resumo
A procura por alimentos mais saudáveis e de maior qualidade, coletados em ambientes naturais e sem o uso de agrotóxicos são o destaque das plantas alimentícias não convencionais ganhando assim reconhecimento pela capacidade de melhorar a qualidade na alimentação de muitas famílias rurais e urbanas. As hortaliças não convencionais são aquelas com distribuição limitada, restringidas a determinadas localidades, tendo grande peso na alimentação e na cultura de populações tradicionais. Além disso, são espécies que não estão organizadas enquanto cadeia produtiva, não despertando o interesse comercial por parte das empresas do setor. Diante do exposto o objetivo deste trabalho foi realizar pesquisa de campo com grupos de interesse potencial em PANC traçando seu perfil de consumo e identificar as PANC mais comumente encontradas em feiras de produtos orgânicos e agroecológicos no interior e capital Alagoana. Foram feitas visitas de campo as feiras de Maceió em que haviam relatos de comercialização das PANC e pesquisa com grupos de potencial interesse na temática de PANC: grupos de consumidores de produtos orgânicos e agroecológicos, grupos sobre o tema em redes sociais e alunos de agroecologia do campus Maragogi/IFAL. Todos os participantes assinaram termo de consentimento livre e esclarecido. A pesquisa com grupos de interesse indicou que há público alvo tanto para a comercialização das PANC como também para produtos educacionais voltados a essa temática. Há várias opções de PANC que poderiam ser comercializadas pelos moradores dos assentamentos, seja in natura ou em produtos processados (agregando valor), assim podendo contribuir com a renda familiar.
\end{abstract}

Palavras-chave: Soberania alimentar; Biodiversidade; Agroecologia; Educação ambiental.

\begin{abstract}
The search for healthier and higher quality food, collected in natural environments and without the use of pesticides is the highlight of non-conventional food plants, thus gaining recognition for the ability to improve the quality of food for many rural and urban families. Non-conventional vegetables are those with limited distribution, restricted to certain locations, having great weight in the food and culture of traditional populations. In addition, they are species that are not organized as a production chain, not arousing commercial interest on the part of companies in the sector. Given the above, the objective of this work was to conduct field research with potential interest groups in PANC tracing their consumption profile and identify the PANC most commonly found in fairs of organic and agroecological products in the interior and capital of Alagoas. Field visits were made to the fairs in Maceió where there were reports of commercialization of PANCs and research with groups of potential interest in the theme of PANC: groups of consumers of organic and agroecological products, groups on the topic in social networks, and students of
\end{abstract}


agroecology of the Maragogi / IFAL campus. All participants signed an informed consent form. The research with interest groups indicated that there is a target audience both for the commercialization of PANCs and also for educational products focused on this theme. There are several PANC options that could be commercialized by the residents of the settlements, either in natura or in processed products (adding value), thus being able to contribute to the family income.

Keywords: Food sovereignty; Biodiversity; Agroecology; Environmental education.

\section{Resumen}

La búsqueda por comidas más sanas y de más calidad, colectadas en ambientes naturales y sin el uso de agrotóxicos son el fuerte de las plantas alimenticias no convencionales, ganando así reconocimiento por la capacidad de mejorar la calidad en la alimentación de muchas familias rurales y urbanas. Las hortalizas no convencionales son aquellas con distribución limitada, restringidas a determinados sitios, teniendo gran peso en la alimentación y en la cultura de poblaciones tradicionales. Además, son especies que no están organizadas como cadena productiva, no despertando el interés comercial por parte de las empresas del sector. Ante lo expuesto, el objetivo de este trabajo ha sido realizar una investigación de campo con grupos de interés potencial en PANC trazando su perfil de consumo e identificar las PANC más comúnmente encontradas en ferias de productos orgánicos y agroecológicos en el interior y en la capital de Alagoas. Fueron hechas visitas de campo a ferias de Maceió en que existían relatos de comercialización de PANC e investigación con grupos de potencial interés en la temática de las PANC: grupos de consumidores de productos orgánicos y agroecológicos, grupos a respeto del tema en redes sociales y alumnos de agroecología del campus Maragogi/IFAL. Todos los participantes firmaron formulario de consentimiento libre y aclarado. La investigación con grupos de interés indicó que existe público tanto para la comercialización de las PANC como también para productos educacionales con esa temática. Existen diversas opciones de PANC que podrían ser comercializadas por los residentes de los asentamientos, sea in natura o en productos procesados (añadiendo valor), contribuyendo de esa manera con el sueldo familiar.

Palabras clave: Soberanía alimentar; Biodiversidad; Agroecología; Educación ambiental.

\section{Introdução}

No decorrer da história humana, uma variedade de plantas vem sendo utilizada como fonte de alimentação, seja de forma direta (consumo direto) ou indireta (alimentação de animais que serão destinados para o consumo humano). Assim, a utilização das plantas com finalidade alimentícia representa alternativa de subsistência para comunidades rurais, além de geralmente contribuírem com a economia local e regional (Nesbitt et al., 2010).

Sob outra perspectiva, Neto (1985) cita que a modernização da agricultura proporcionou por um lado benefícios para os envolvidos no agronegócio, mas teve como consequência para outros, como os agricultores familiares, dificuldades de reprodução e viabilização de sua produção diante das barreiras impostas pelo mercado, demonstrado a insustentabilidade do ponto de vista socioambiental, pois o que acaba predominando nesse modelo é a maximização do lucro e da produção, não levando em consideração os aspectos sociais das famílias agricultoras.

Em adição, Toledo e Barrera-Bassols (2015) dizem que a implementação de um conjunto de tecnologias atualizadas, como sementes melhoradas, fertilizantes químicos e agrotóxicos, fez com que muitos agricultores abandonassem todas as práticas historicamente construídas, ocorrendo não só a mudança nessa base técnica, mas também na lógica de gestão do conhecimento, pois com a perda de sementes nativas, perde-se também os conhecimentos necessários para o cultivo dessas sementes. Da mesma forma ocorre com o uso da matéria orgânica e outras práticas que o homem do campo deixou de realizar. Esse fenômeno é chamado de perda da memória biocultural.

Tavares e Ramos (2006) informam que até alguns anos atrás os recursos alimentares não convencionais eram vistos como símbolos do atraso socioeconômico de algum indivíduo, região ou país. No entanto, devido à procura por alimentos mais saudáveis e de maior qualidade, coletados em ambientes naturais e sem o uso de agrotóxicos, as espécies não convencionais vêm ganhando reconhecimento como fatores potencialmente capazes de melhorar a qualidade na alimentação de muitas famílias rurais e urbanas (Zuin \& Zuin, 2008).

No passado, muitas espécies não convencionais foram amplamente utilizadas na alimentação diária de famílias rurais (mendes, 2006), mas as alterações nos hábitos alimentares, causadas pela modernização da agricultura, o êxodo rural, o 
desmatamento e a urbanização da zona rural, acarretaram na redução da diversidade no consumo e na produção de alimentos (Mariante et al., 2008).

O Brasil é um país de proporções continentais, seus 8,5 milhões km² ocupam quase a metade da América do Sul. Essa extensão cria uma grande variedade de biomas, e isso reflete na enorme riqueza da diversidade biológica brasileira. Mais de $20 \%$ do número total de espécies da Terra estão no Brasil, e por essa razão o país abriga a maior biodiversidade do planeta, ocupando o posto de principal nação entre os 17 países com maior heterogeneidade biológica (Brasil, 2010).

De acordo com Manual de Hortaliças Não Convencionais do Ministério da Agricultura, Pecuária e Abastecimento MAPA (Brasil, 2010), as hortaliças não convencionais são aquelas com distribuição limitada, restringidas a determinadas localidades, tendo grande peso na alimentação e na cultura de populações tradicionais. Além disso, são espécies que não estão organizadas enquanto cadeia produtiva propriamente dita, diferentemente das hortaliças convencionais, como a batata, tomate, entre outras. Por essa razão, acabam por não despertar o interesse comercial por parte das empresas do setor.

O objetivo deste trabalho foi realizar pesquisa de campo com grupos de interesse potencial em PANC traçando seu perfil de consumo e identificar as PANC mais comumente encontradas em feiras de produtos orgânicos e agroecológicos no interior e capital Alagoana.

\section{Metodologia}

A pesquisa científica, no que diz respeito a sua finalidade, foi do tipo aplicada, voltada para a aquisição de conhecimento empírico, adquirido através das experiências relatadas pelos entrevistados e quanto ao objetivo, foi uma pesquisa descritiva, que apresentou abordagem tanto de aspectos quantitativos como de aspectos qualitativos. Com relação aos procedimentos de coleta da informação, foram realizadas a pesquisa bibliográfica, estudo de caso e pesquisa de campo.

Os dados quantitativos foram tratados em planilha eletrônica, que serviram de base para a criação dos gráficos e tabelas apresentados.

A abordagem da pesquisa foi do tipo qualitativa utilizando-se a pesquisa-ação, conforme descrito por Baldissera (2001), consistindo assim em obter os dados nas próprias comunidades avaliadas, valorizando o saber e a prática diária dos entrevistados, buscando por soluções para determinadas questões locais, unindo assim a ciência com mudanças positivas para a realidade de vida dessas comunidades.

Foram feitas visitas de campo as feiras de Maceió em que haviam relatos de comercialização das PANC. Foi realizada pesquisa com grupos de potencial interesse na temática de PANC: grupos de consumidores de produtos orgânicos e agroecológicos, grupos sobre o tema em redes sociais e alunos de agroecologia do campus Maragogi/IFAL.

Os participantes da pesquisa assinaram termo de consentimento livre e esclarecido o qual declarava aceitar participar por sua própria vontade, sem receber qualquer incentivo financeiro ou ter qualquer ônus e com a finalidade exclusiva de colaborar para o sucesso da pesquisa. O pesquisado também foi informado(a) dos objetivos estritamente acadêmicos do estudo e que sua colaboração se faria de forma anônima.

Para obtenção das respostas, utilizou-se o formulário de pesquisas online "Google Forms". O formulário ficou aberto para respostas no período de 12/03/2019 a 29/04/2019. Os dados obtidos foram tratados em planilha eletrônica, que serviram de base para a criação dos gráficos.

Durante as entrevistas e conversas com moradores de assentamentos, identificou-se que a comercialização da produção é feita em diversas feiras orgânicas e agroecológicas que ocorrem em Maceió/AL.

Ao realizar a pesquisa em meios de comunicação, como redes sociais e sítios eletrônicos de notícias do Estado, constatou-se a comercialização de algumas espécies de PANC nas feiras locais.

Por essas razões, optou-se por realizar visitas in loco a algumas feiras que ocorrem na capital do Estado, buscando 
observar questões importantes relativas ao presente trabalho. Essas visitas ocorreram entre novembro de 2018 e junho de 2019.

\section{Resultados e Discussão}

\section{Pesquisa com grupos de interesse}

Os grupos de interesse foram compostos por consumidores de produtos orgânicos e agroecológicos, alunos de agroecologia do campus Maragogi/IFAL e grupos interessados em PANC encontrados em redes sociais. No total houve 187 participantes na pesquisa através do formulário online.

Ao serem questionados sobre a familiaridade com o termo "PANC", $87,7 \%$ dos entrevistados indicaram já ter ouvido falar.

Em torno de 67\% dos entrevistados afirmaram que consomem corriqueiramente plantas ou parte de plantas que não são normalmente comercializadas. Esse resultado pode indicar que há um potencial de comércio com as PANC que poderia ser explorado.

Quando consultados de que forma conheceram as PANC, 30,53\% dos entrevistados relataram que foi através da internet (Figura 1), embora uma parcela considerável tenha conhecido através de alguém, de um livro sobre o tema, de disciplina em curso, escola ou faculdade e matéria em programas de televisão.

Figura 1. Meio através do qual os entrevistados dos grupos de interesse conheceram as PANC.

\section{COMO CONHECEU AS PANC?}

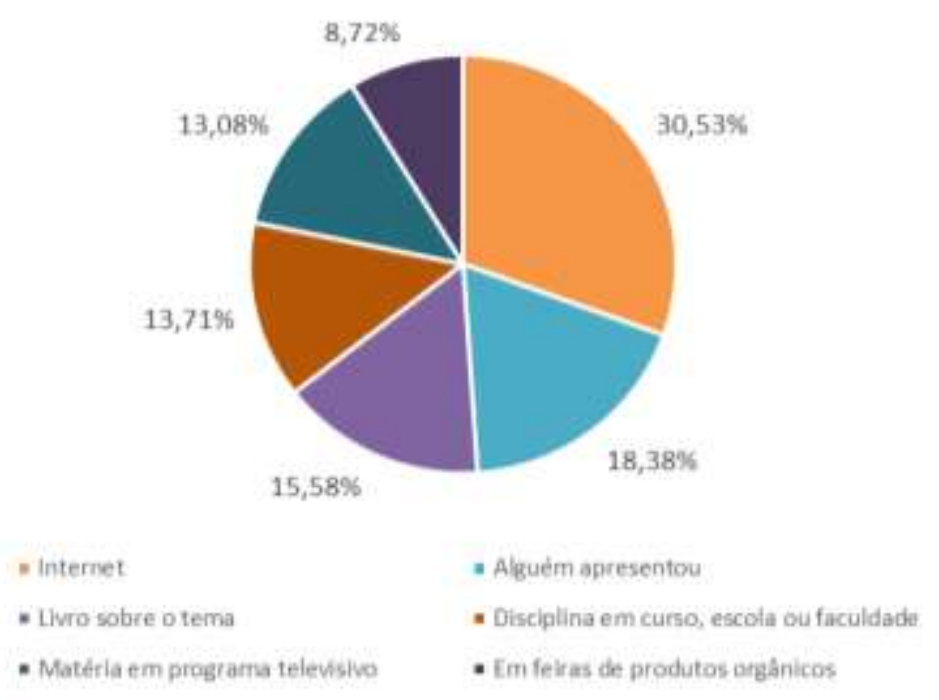

Fonte: Autores.

Apenas $8,72 \%$, isto é, a minoria citou as feiras de produtos orgânicos como fonte primordial do contato com as PANC, indicando a necessidade de um trabalho melhor de divulgação sobre essas espécies não convencionais nessas localidades, já que geralmente é um nicho de possíveis interessados. Trabalhos em educação ambiental utilizando ferramentas inovadoras como aplicativos para dispositivo móvel (https://play.google.com/store/apps/details?id=co m.infopancs\&hl=pt_BR\&gl=US\&showAllReviews=true) e cartilha (https://www2.ifal.edu.br/ppgtec/produtos-tecnicotecnologicos-ptts/arquivos/cartilha-panc_patelo-t.pdf) podem contribuir para uma maior divulgação da temática.

Quando indagados sobre em qual localidade os mesmos obtêm essas plantas ou partes de plantas não convencionais (Figura 2), mais da metade dos entrevistados indicou o local em que reside como fonte, seguido, respectivamente, de produtores locais e em feiras de bairro ou munícipio. 
Figura 2. Local em que os entrevistados dos grupos de interesse obtêm plantas/partes da plantas que normalmente não são comercializadas.

\section{LOCAL EM QUE ESSAS PLANTAS/PARTES DE PLANTAS SÃO OBTIDAS}

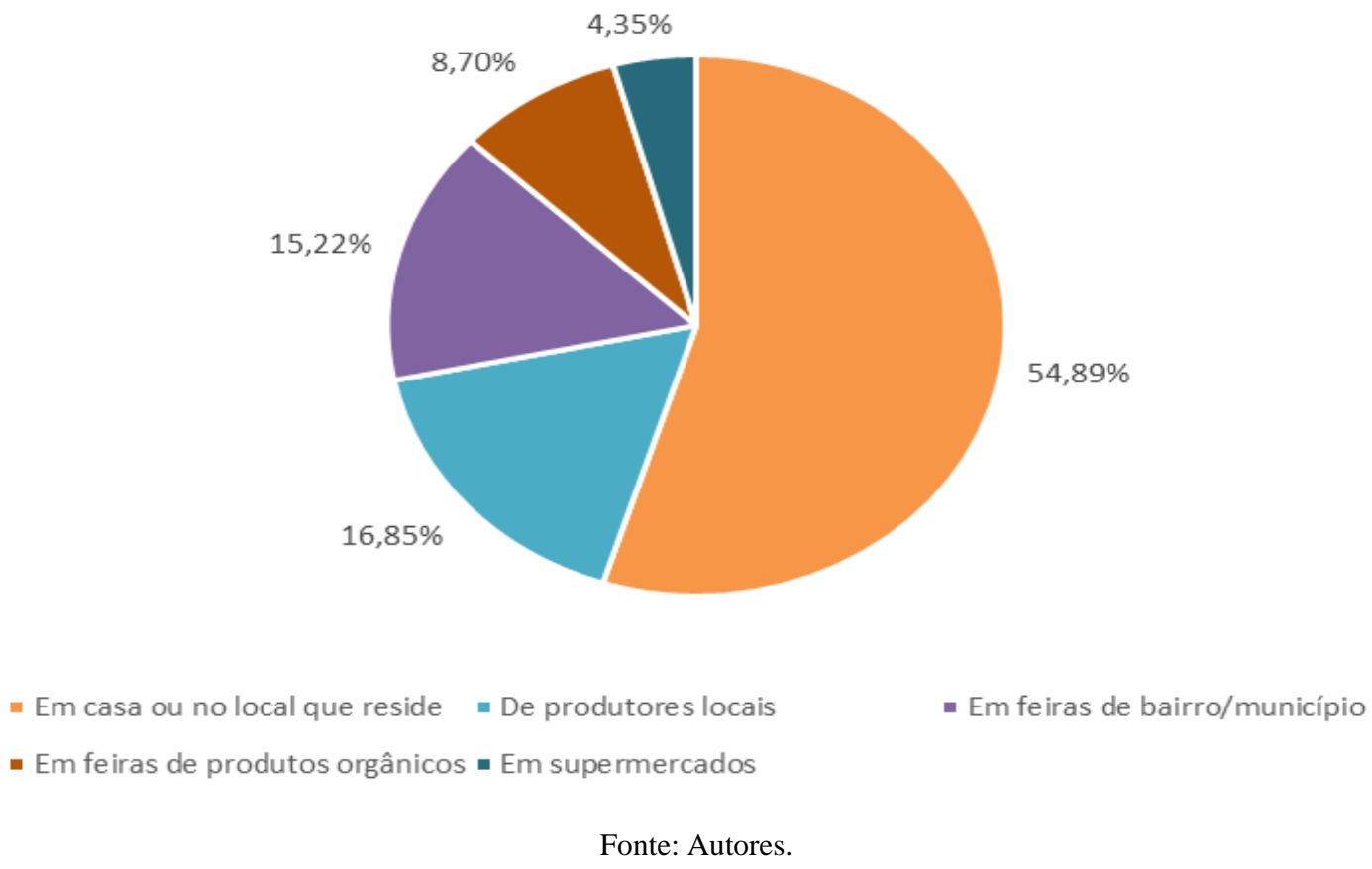

Observa-se que enquanto 15,22\% dos entrevistados conseguem as PANC em feiras de bairro/município, apenas 8,7\% as obtêm em feiras de produtos orgânicos, sendo necessário uma investigação mais profunda para entender esse fato, já que o público alvo de feiras orgânicas geralmente pode se interessar no consumo de PANC.

De acordo com a Figura 3, em torno de 37\% dos entrevistados informaram que consomem as PANC porque a sabedoria familiar ou popular indica, possivelmente porque o consumo dessas espécies está ligado ao conhecimento passado entre gerações da mesma família, e em muitos casos de comunidades restritas.

Uma parcela considerável indicou que o consumo ocorre pelo fato de a planta ser comum na região em que mora, e por ser subproduto de outra espécie vegetal. Nesse sentido, é possível perceber que pode haver uma correlação com o local em que o entrevistado reside e o motivo pelo qual as PANC são consumidas. 
Research, Society and Development, v. 10, n. 4, e27710414146, 2021

(CC BY 4.0) | ISSN 2525-3409 | DOI: http://dx.doi.org/10.33448/rsd-v10i4.14146

Figura 3. Motivos de consumo das PANC pelos entrevistados dos grupos de interesse.

\section{MOTIVOS PARA CONSUMIR PLANTAS/PARTES DE PLANTAS QUE NORMALMENTE NÃO SÃO COMERCIALIZADAS?}

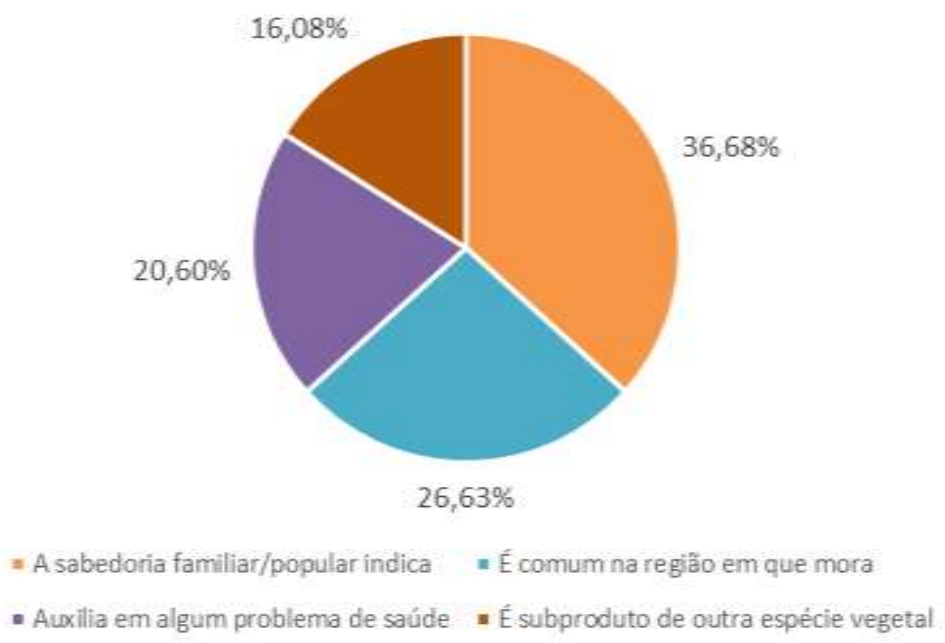

Fonte: Autores.

Os entrevistados também foram questionados sobre o interesse de consumir algumas espécies conhecidas de PANC e que também são comuns no estado de Alagoas (Figura 4). A maioria demonstrou interesse em diversas plantas, destacando-se a ora-pro-nóbis (Pereskia aculeata Mill.), a taioba (Xanthosoma taioba E. G. Gonç) o coração ou mangará da bananeira (Musa X paradisiaca L.) e a papoula ou hibisco (Hibiscus rosa-sinensis).

Figura 4. Disposição dos entrevistados dos grupos de interesse em consumir determinadas PANC.

\section{DISPOSIÇÃO PARA CONSUMIR DETERMINADAS PANC}

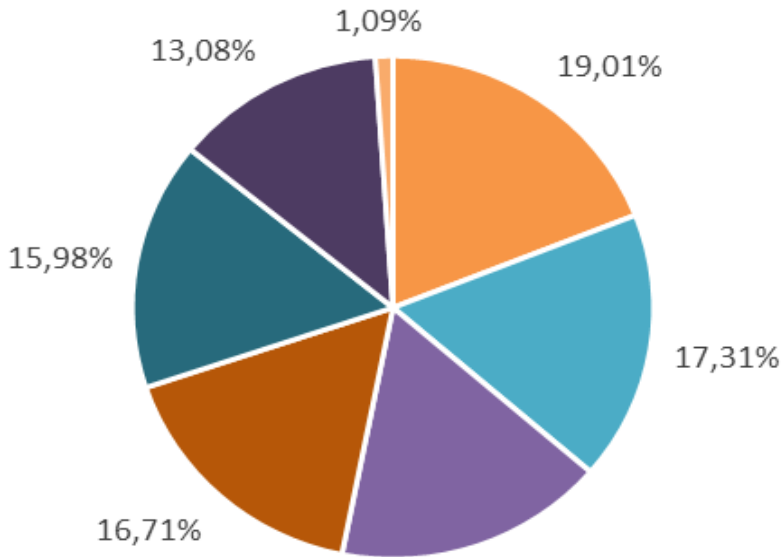

$16,83 \%$

- Ora-pro-nóbis

- Papoula/Hibisco

- Nenhuma das opçôes
" Coração/Mangará da Bananeira - Taioba

- Azedinha (Limão-Caieno)

- Batata-da-praia/Salsa-da-praia

Fonte: Autores. 
Kinupp e Lorenzi (2014) afirmam que a banana é um fruto bastante popular e amplamente cultivado em regiões tropicais, incluindo o Brasil. No entanto, há valor nutricional nas partes não convencionais da bananeira, como o mangará (umbigo ou coração), o palmito (parte interna do pseudocaule) e flores (Figura 5).

O próprio fruto da bananeira, no caso a banana verde, vem sendo utilizada de forma não convencional, para produção de biomassa verde e chips de banana verde. Além desse uso, as cinzas oriundas da queima da parte aérea da planta podem ser usadas como substitutas do sal (Kinupp \& Lorenzi, 2014).

Apesar da carência de estudos bromatológicos relacionados as partes não convencionais da bananeira, ocasionalmente pode-se encontrar o coração sendo vendido em feiras e mercados públicos, como verdura ou para fins medicinais, na forma de xarope (Kinupp \& Lorenzi, 2014).

Ao pesquisar por produtos processados com o coração da bananeira, encontrou-se um tipo de produto que simula um preparo culinário comum, a "carne” louca de mangará, conforme mostra a Figura 6.

Figura 5. Conserva com as inflorescências do coração da bananeira.

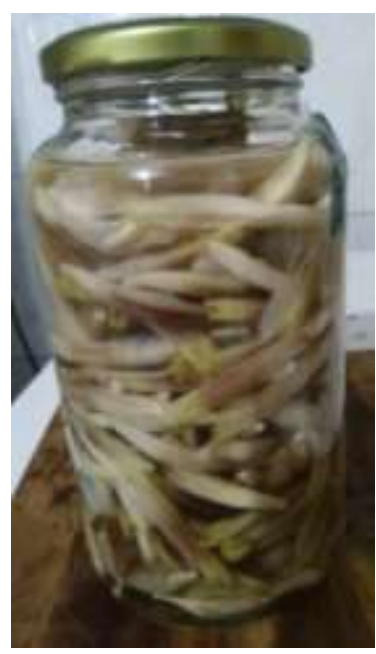

Fonte: Autores.

Figura 6. Produto processado contendo mangará da bananeira.

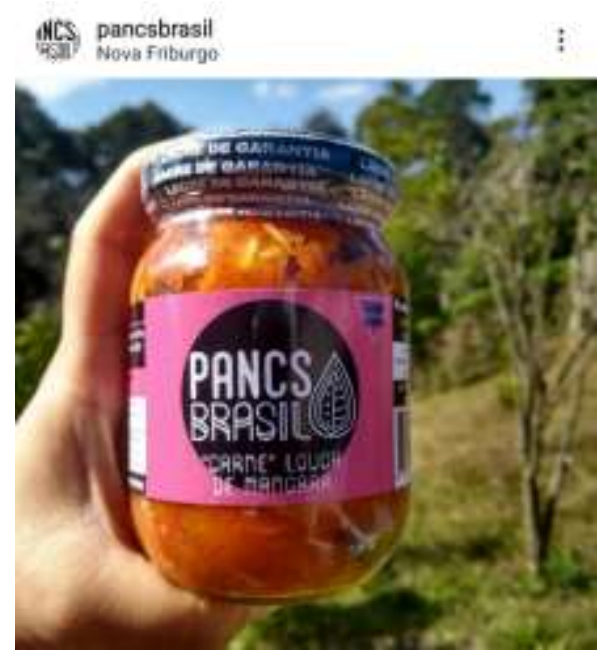

Fonte: https://www.instagram.com/pancsbrasil 


\section{Feiras agroecológicas e orgânicas em Maceió/AL}

Santos et al. (2014) dizem que a feira tem sua significância social e econômica à medida que contribui para o bemestar da família produtora e para sociedade, através da melhoria da qualidade de vida e saúde, como também no aumento da renda do núcleo familiar. Com relação ao aspecto ambiental, os produtos comercializados são produzidos com a preocupação de manter saudáveis o solo, os trabalhadores e a sociedade.

Dessa forma, a produção agroecológica, assim como as feiras de economia solidária, são uma alternativa à sustentabilidade das famílias do campo, pois consideram fatores que vão além da questão econômica, fortalecendo a agricultura familiar. A agroecologia possibilita aos agricultores determinado grau de sustentabilidade socioeconômica e ambiental, possibilitando as famílias do campo a desenvolverem condições necessárias para a sobrevivência. Assim, com o devido suporte técnico, os agricultores podem entender a viabilidade da produção agroecológica, e o fato de a comercialização ocorrer em grupo favorece o reconhecimento da agricultura familiar, bem como possibilita a permanência das famílias no campo (Santos et al., 2014).

Através de uma imagem disponibilizada em uma rede social (Figura 7), identificou-se vários restaurantes na cidade de Maceió/AL com potencial de uso das PANC, além de diversas feiras de produtos orgânicos e agroecológicos na capital alagoana, algumas em quais os entrevistados dos assentamentos já comercializam suas produções.

Figura 7. Estabelecimentos e feiras que comercializam produtos orgânicos e agroecológicos em Maceió/AL.

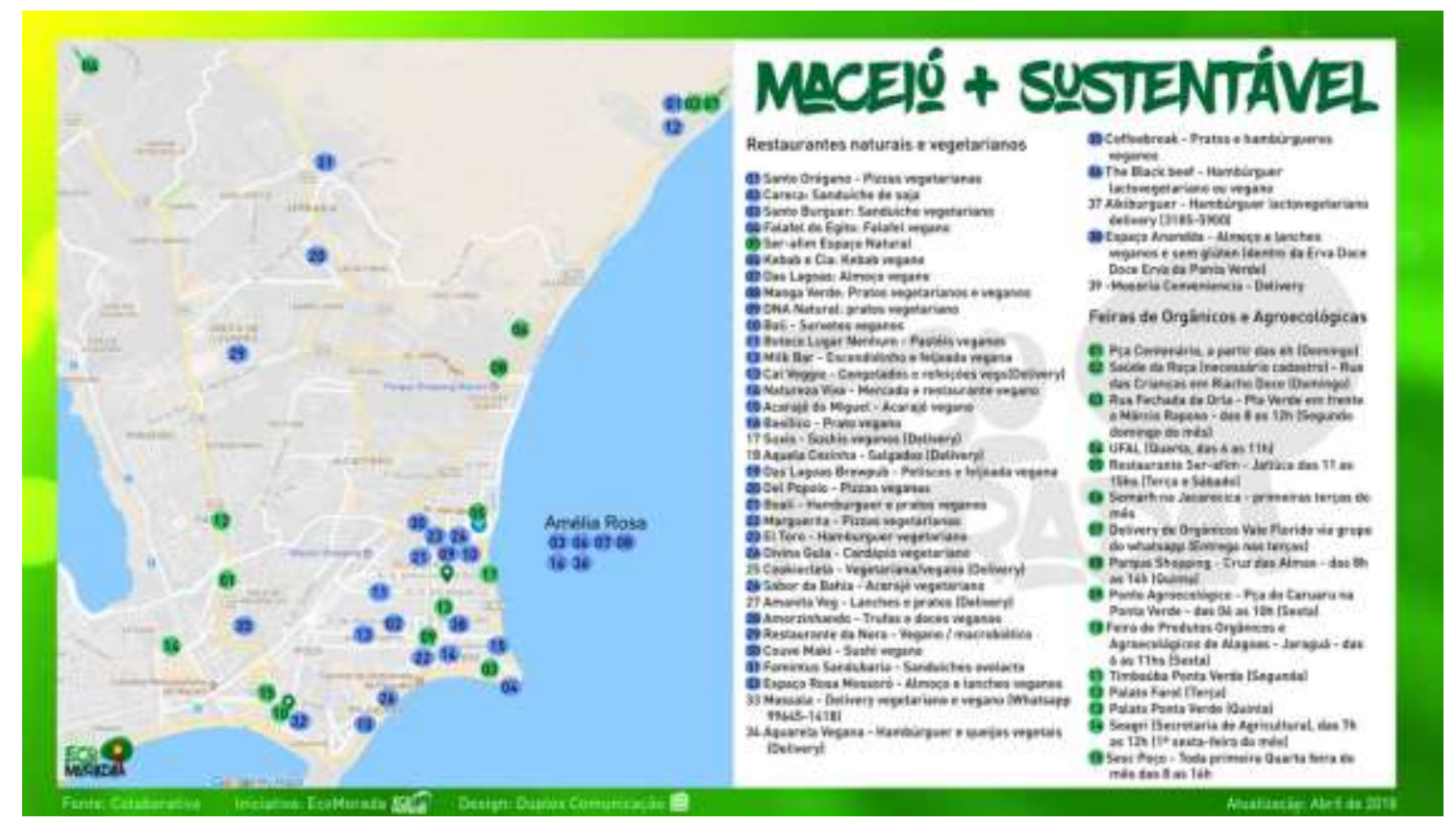

Fonte: https://www.facebook.com/ecomoradavidasustentavel/

A primeira feira visitada foi a realizada pela Secretaria da Agricultura do Estado de Alagoas (SEAGRI/AL), localizada no centro da cidade de Maceió (Figura 8). O evento ocorre toda primeira sexta-feira do mês em um espaço disponibilizado na própria Secretaria. 
Research, Society and Development, v. 10, n. 4, e27710414146, 2021

(CC BY 4.0) | ISSN 2525-3409 | DOI: http://dx.doi.org/10.33448/rsd-v10i4.14146

Figura 8. Feira de produtos orgânicos e agroecológicos promovida pela SEAGRI/AL.

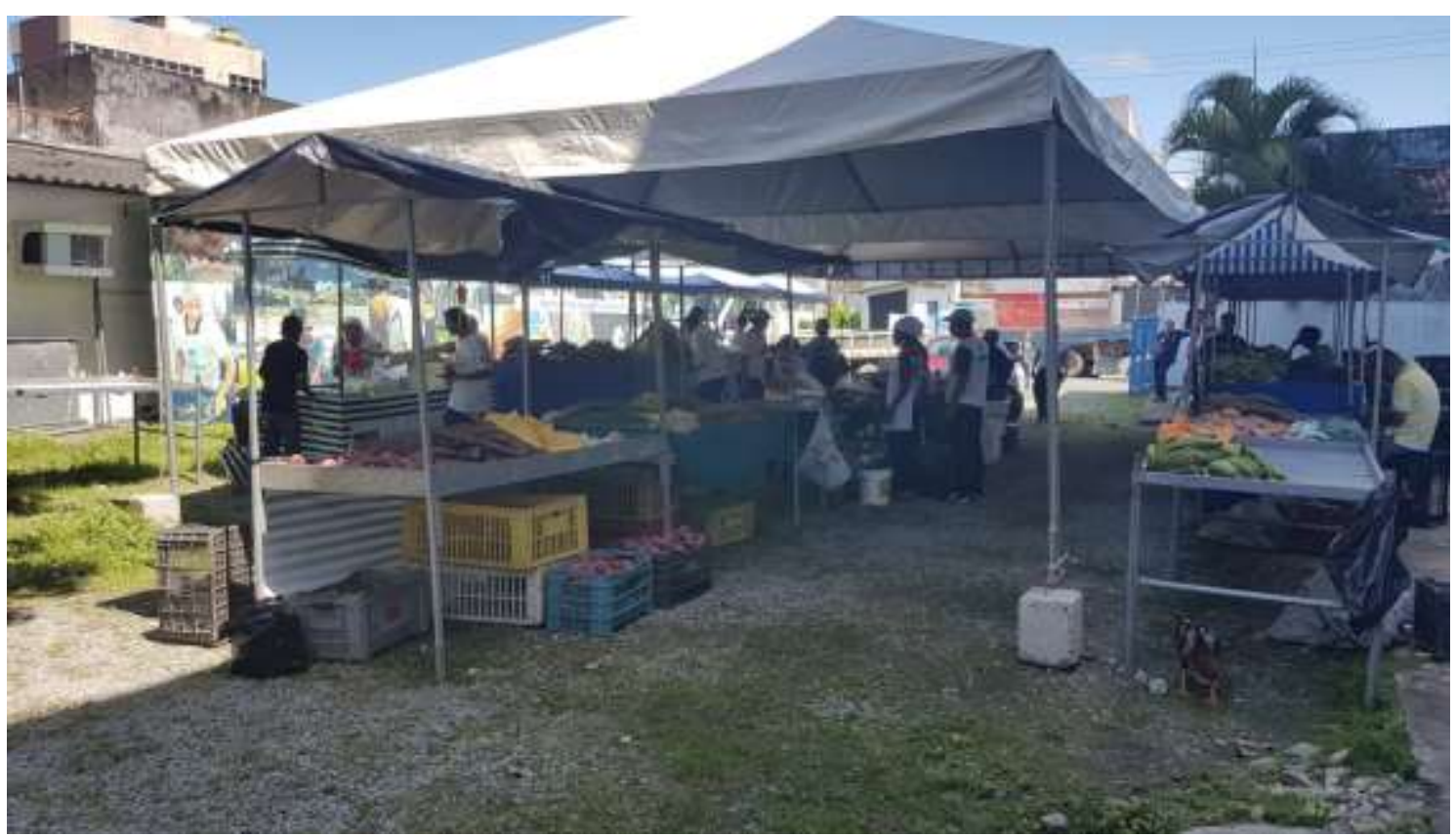

Fonte: Autores.

Nessa feira foi identificada a comercialização da PANC taioba (figura 9), tanto in natura quanto em produto derivado (bolo). Além disso, no dia em que foi realizada a visita estava ocorrendo uma oficina de preparo e degustação de pratos com PANC.

Figura 9. Comercialização da PANC Xanthosoma taioba E. G. Gonç. (em destaque).

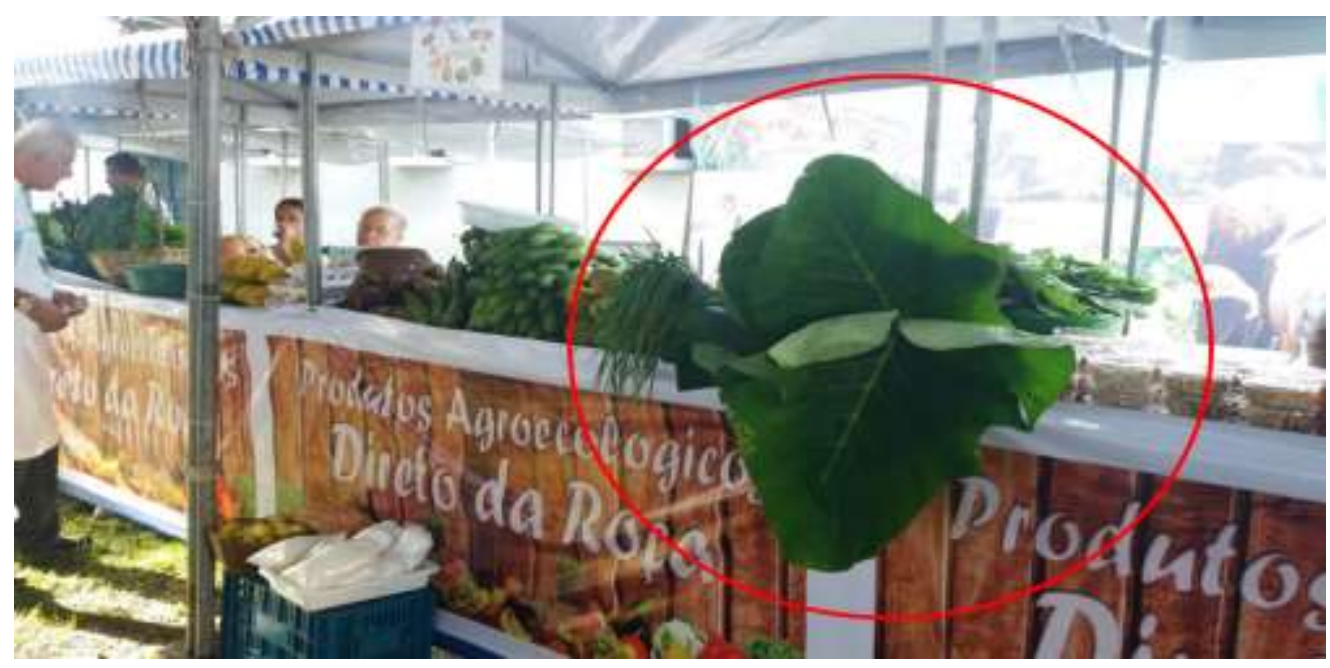

Fonte: Autores.

Nessa oficina, além da taioba, também foi possível identificar (Figura 10) os seguintes preparos contendo PANC: geleia produzida com hibisco/papoula (Hibiscus rosa-sinensis), folhas de moringa (Moringa oleifera), pétalas de ixora pink (Ixora L.) e aroeira vermelha (Schinus terebinthifolius Raddi).

Padilha et al. (2017), em um estudo que buscou as PANC como alternativa para a gastronomia do estado de Pernambuco, identificaram que a taioba é pouco conhecida na culinária da região Nordeste, mas existe em quintais domésticos. Essa espécie reúne características que a tornam recomendada para compor o cardápio doméstico ou de restaurantes. A taioba 
tem potencial para contribuir de forma expressiva na dieta humana quando consumida na quantidade adequada, devido a qualidade de seus nutrientes e compostos bioativos. Devidamente valorizada, poderia auxiliar na mudança da visão que se tem de ser erva daninha ou praga da lavoura, assim colaborando em evitar a extinção dessa espécie.

Até pouco tempo a utilização como condimento da aroeira vermelha era pouco conhecida no Brasil, no entanto é citada em diversos livros de alta gastronomia e de receitas nacionais e internacionais. Pode ser usada como substituta da pimenta-do-reino, e é comercializada em supermercados, sendo seu preço bem elevado (Kinupp \& Lorenzi, 2014).

Figura 10. Pratos com PANC apresentados em oficina na Feira da SEAGRI/AL.
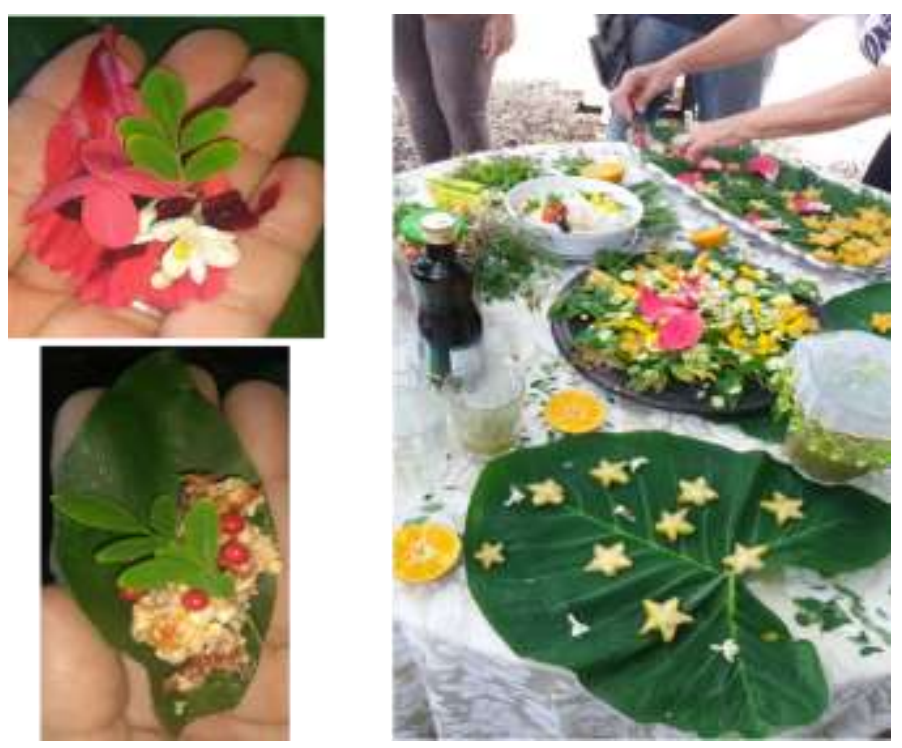

Fonte: Autores.

Outra feira visitada ocorre todos os domingos a partir de seis horas da manhã, em um local conhecido da cidade de Maceió, a Praça Centenário. Nesta, um grupo dedicado a disseminação em Alagoas de conhecimento relativo às PANC periodicamente comercializa algumas espécies, e no dia estavam à venda os cálices florais da vinagreira, Hibiscus sabdariffa L.

Kinupp e Lorenzi (2014) informam que a Hibiscus sabdariffa L., mais conhecida como vinagreira na região Norte do Brasil, é mundialmente cultivada, tanto para uso ornamental como para produção de frutos, cujos cálices florais carnosos e imaturos apresentam uso culinário, principalmente molhos, chás, sucos, geleias e refrescos. Os cálices florais também têm grande potencial para a produção de sorvetes e picolés.

De acordo com Mans e Grant (2017), preparações com os cálices florais da Hibiscus sabdariffa são utilizadas no sistema medicinal de muitos povos, para o tratamento de uma gama de distúrbios, como infecção microbiana, tosses, bronquites, problemas nos rins e gastrointestinais.

Essa espécie é rica em antocianinas, e suas folhas jovens e sementes também podem ser consumidas, após o devido preparo culinário. As sementes maduras torradas e moídas dão origem a uma farinha que pode ser utilizada no preparo de pães (Kinupp \& Lorenzi, 2014).

Em visita de campo no assentamento Dom Hélder Câmara (Murici/AL) constatou-se a existência da Hibiscus sabdariffa $\mathrm{L}$. em vários locais, tanto é que 5\% dos entrevistados nessa comunidade indicaram que conheciam essa espécie.

Visto que essa espécie é comum no assentamento Dom Hélder Câmara em Murici, algumas espécies poderiam ser utilizadas como matéria-prima para produtos processados, aumentando o valor agregado, e comercializados pelos moradores, 
como a farinha das sementes e os cálices florais secos, podendo assim gerar uma contribuição significativa para a renda familiar.

A Hibiscus sabdariffa L. foi chamada pelos entrevistados dos assentamentos de "hibisco", porém não deve ser confundindo com a espécie Hibiscus rosa-sinensis, sendo esta chamada pela comunidade de "papoula". Então, apesar de ambas ocorrerem nos assentamentos e possuírem coincidentemente um nome popular em comum, são espécies distintas.

Embora a Moringa oleifera tenha sido citada apenas por dois entrevistados no assentamento Junco, é uma espécie de PANC que tem certo destaque. De acordo com Kinupp e Lorenzi (2014), essa espécie tem divulgação recente no Brasil, é muito cultivada em quintais na região Nordeste do país, principalmente para uso medicinal.

Essa espécie é tem grande importância na culinária indiana, servindo de ingrediente em diversos preparos culinários. As folhas têm alto teor de carotenoides e é uma das melhores fontes entre as verduras de pró-vitamina A, podendo ser usadas como a maioria das hortaliças. Já os frutos de algumas variedades, quando tenros e bem jovens podem ser raspados e cozidos como vagem de feijão. As raízes engrossadas podem ser desenterradas, descascadas e raladas para uso como condimento similar a raiz-forte (Kinupp \& Lorenzi, 2014).

Santos et al. (2011) explicam que a moringa é uma árvore de pequeno porte, rústica, tolerante à seca, de crescimento rápido e que se adapta em uma ampla faixa de solo. Por essas razões, pode ser facilmente propagada. É considerada uma das árvores mais úteis para o ser humano, pois quase todas as suas partes possuem valor alimentício e medicinal.

Em Alagoas, um projeto desenvolvido pela ONG Associação Comunitária e Beneficente Vila Ana Maria (ABEVILA), em uma escola no município de Paripueira, está utilizando folhas de moringa na alimentação de crianças em creche (Portal G1, 2019).

De acordo com a nutricionista da creche, a moringa é acrescentada na sopa, no feijão, na carne e demais alimentos, não alterando o sabor destes (Portal G1, 2019). Pelo fato de apresentar bons teores de nutrientes diversificados, essa espécie pode ser utilizada como uma boa opção de suplementação alimentar.

Foi encontrada em uma cooperativa de produtores a comercialização de folhas secas da moringa (Figura 11), com 100 gramas custando $\mathrm{R} \$ 34,99$. Por se tratar de espécie que cresce facilmente e sem muitos tratos culturais, essa espécie poderia ser plantada pelos moradores do assentamento, formando uma cadeia produtiva e gerando uma fonte de renda para os assentados.

Figura 11. Comercialização de folhas secas de Moringa (Moringa oleifera).

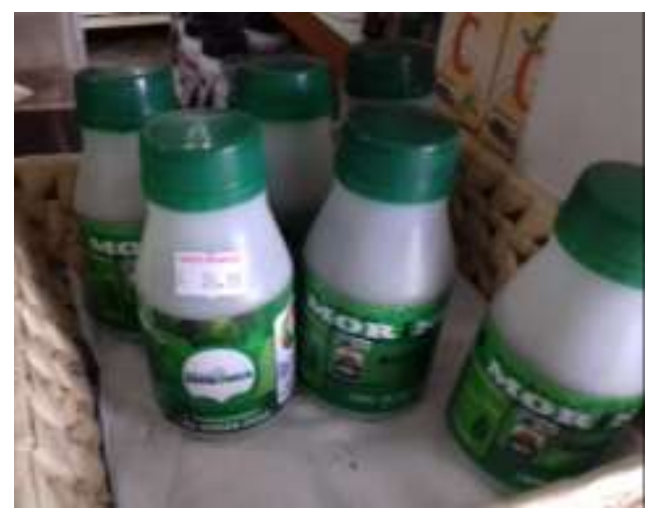

Fonte: Autores.

Embora a moringa faça parte da cultura popular, a ANVISA recentemente proibiu a fabricação, a importação, a comercialização, a propaganda e a distribuição de todos os alimentos que contenham essa planta. A medida, válida para todo o território nacional, abrange tanto alimentos que contenham essa espécie como constituinte, em quaisquer formas de apresentação, como chá, cápsulas etc., quanto o próprio insumo (ANVISA, 2019). 
A medida foi tomada diante do fato de não haver avaliação e comprovação de segurança do uso dessa planta em alimentos. Além disso, foi constatado que há inúmeros produtos denominados e/ou constituídos de Moringa oleifera que vêm sendo irregularmente comercializados e divulgados com diversas alegações terapêuticas não permitidas para alimentos, como por exemplo: cura de câncer, tratamento de diabetes e de doenças cardiovasculares, entre muitas outras (ANVISA, 2019).

Essa proibição da ANVISA pode ser considerada coerente, pois em muitos casos os brasileiros têm a cultura de se automedicar, seja por medicina alternativa ou por medicamentos convencionais sem a devida avaliação profissional, podendo agravar a condição de saúde e tornando ineficaz um tratamento que poderia ser utilizado em tempo hábil após o correto diagnóstico. Nesse sentido, Silveira (2019) cita um recente levantamento no Brasil, em que constatou-se que 64\% dos entrevistados praticam a automedicação.

Essa situação reforça a necessidade crescente de pesquisas relacionadas às PANC, para haver um arcabouço científico que possa servir de embasamento para o público em geral ao tomar a decisão acerca dos benefícios que a inserção dessas espécies na alimentação do dia-a-dia pode trazer.

Em consonância, Messias et al. (2015) realizaram estudo sobre o uso popular de plantas medicinais e perfil socioeconômico dos usuários em área urbana na cidade de Ouro Preto/MG, e identificaram que o conhecimento sobre o uso tradicional dos recursos tem se revelado como uma ferramenta para valorização dos bens naturais e estímulo a preservação ambiental. Os resultados obtidos pelos autores podem subsidiar a bioprospecção de novos fármacos, assim como nortear futuras ações extensionistas no município na área ambiental e da saúde.

Estudo feito por Bezerra e Santos Filho, (2021) informam que pesquisas relacionadas a plantas alimentícias não convencionais ainda são incipientes. No entanto, já existem movimentos de popularização do conhecimento e algumas espécies vegetais são utilizadas a nível local por comunidades tradicionais e difundidas para centros urbanos em feiras e mercados.

Durante as visitas as feiras em Maceió, em conversas com os feirantes percebeu-se algumas dificuldades enfrentadas. Precisam acordar bem cedo para carregar o caminhão, que muitas vezes tem que ser custeado com recursos próprios, já que nem sem a Prefeitura do município consegue disponibilizar. Em seguida, se dirigem a alguma feira na capital, descarregam a produção e só então iniciam a comercialização. No fim do dia geralmente voltam com a maior parte da produção. E isso se repete de três a quatro vezes por semana.

Trabalhos científicos voltados para a comprovação dos benefícios trazidos pelo consumo dos tipos de produtos comercializados nessas feiras, bem como um trabalho de divulgação que traduza esses resultados para uma linguagem de fácil entendimento para o público em geral, poderia auxiliar na melhoria dessa situação desgastante para os produtores.

\section{Considerações Finais}

A pesquisa com grupos de interesse indicou que há público alvo tanto para a comercialização das PANC como também para aquisição de produtos educacionais voltados a essa temática, contribuído assim para divulgação.

Os feirantes relataram diversas dificuldades que passam para conseguir chegar as feiras orgânicas e agroecológicas em que comercializam os produtos convencionais, e além disso foram encontradas algumas poucas PANC sendo comercializadas, ou seja, é uma situação que acaba por não despertar o interesse econômico na produção das PANC por parte destes produtores. Um trabalho de maior divulgação dos benefícios trazidos pelos produtos encontrados nessas feiras pode auxiliar na mudança desse cenário.

De forma geral, há muito a ser explorado sobre a temática das PANC. No campus Maragogi do IFAL, além da proximidade com o assentamento Nova Jerusalém, a cantina desse campus é localizada a poucos metros da plantação que possuí coração da bananeira e moringa, por isso em alguma atividade de extensão futura pode-se propor preparos culinários 
com essas PANC, e sugerir a degustação para a própria comunidade acadêmica local. Uma plantação dessa sendo reproduzida para outras unidades do Instituto faria com que fosse possível explorar igualmente essa temática.

Há várias opções de PANC que poderiam ser comercializadas pelos moradores dos assentamentos, seja in natura ou em produtos processados (agregando valor), assim podendo contribuir com a renda familiar do assentados. Por se tratar de espécies rústicas, o custo de produção não seria elevado.

\section{Agradecimentos}

A equipe técnica deste trabalho agradece a todos os participantes do projeto PANC em Maragogi.

\section{Referências}

Agência Nacional De Vigilância Sanitária - ANVISA. (2019). Proibidos alimentos com Moringa oleifera. http://portal.anvisa.gov.br/noticias//asset_publisher/FXrpx9qY7FbU/content/proibidos-alimentos-com-moringa-oleifera/219201.

Baldissera, A. (2001). Pesquisa-Ação: Uma metodologia do "conhecer" e do "agir" coletivo. Revista Sociedade em Debate. Universidade Católica de Pelotas, 7(2), 5-25.

Bezerra, M. A. \& Santos Filho, F. S. (2021). Alimentos florestais aquáticos: prospecção científica do potencial nutricional negligenciado. Pesquisa, Sociedade e Desenvolvimento, 10(3), e32510313457.

Kinupp, V. F. \& Lorenzi, H. (2014). Plantas Alimentícias Não Convencionais (PANC) no Brasil: guia de identificação, aspectos nutricionais e receitas ilustradas. Nova Odessa: Instituto Plantarum de Estudos da Flora. 768 p.

Mans, D. R. A. \& Grant, A. (2017). “A thing of beauty is a joy forever”. Plants and plant-based preparations for facial care in Suriname. Clinical and Medical Investigation, 2(4), 1-16.

Mariante, A. S., Sampaio, M. J. A. \& Inglis, M. C. V. (2008). Informe nacional sobre a situação dos recursos fitogenéticos para a alimentação e a agricultura do Brasil. EMBRAPA, 21-29.

Messias, M. C. T. B., Menegatto, M. F., Prado, A. C. C., Santos B. R. \& Guimarães, M. F. M. (2015). Uso popular de plantas medicinais e perfil socioeconômico dos usuários: um estudo em área urbana em Ouro Preto, MG, Brasil. Revista Brasileira de Plantas Medicinais, 17(1), 76-104.

Nesbitt, M., Mcburney, R. P. H., Broin, M. \& Beentje, H. J. (2010). Linking biodiversity, food and nutrition: The importance of plant identification and nomenclature. Journal of food composition and analysis, 23(6), 486-498.

Neto, F. G. (1985). Questão Agrária e Ecologia: crítica da moderna agricultura. (2a ed.), Brasiliense.

Padilha, M. do R. de F., Shinohara, N. K. S., Shinohara, G. M., Cabral, J. V. B. \& Oliveira, F. H. P. C. De. (2017). Plantas alimentícias não convencionais (PANC): uma alternativa para a gastronomia pernambucana. Anais da Academia Pernambucana de Ciência Agronômica, 13/14, $266-278$.

Portal G1. (2019). Projeto usa folhas da moringa na alimentação de crianças em creche de Paripueira. http://g1.globo.com/al/alagoas/gazetarural/videos/t/edicoes/v/projeto-usa-folhas-da-moringa-na-alimentacao-de-criancas-em-creche-de-paripueira/7350054/.

Santos, C. F. dos, Siqueira, E. S., Araújo, I. T. de \& Maia, Z. M. G. (2014). A agroecologia como perspectiva de sustentabilidade na agricultura familiar. Revista Ambiente \& Sociedade, 18(2), 33-52.

Santos, W. R., Matos, D. B., Oliveira, B. M., Santana, T. M., Santana, M. M. de \& Silva, G. F. da. (2011). Estudo do tratamento e clarificação de água com torta de sementes de Moringa oleífera Lam. Revista Brasileira de Produtos Agroindustriais, 13, 295-299.

Tavares, J. R. \& Ramos, L. R. (2006). Assistência técnica e extensão rural: construindo o conhecimento agroecológico. IDAM, $103-116$.

Toledo, V.M. \& Barrera-Bassols, N. (2015). A memória biocultural: a importância ecológica das sabedorias tradicionais. Expressão Popular. 225.

Zuin, L. F. S. \& Zuin, P. B. (2008). Produção de alimentos tradicionais. Contribuindo para o desenvolvimento local/regional e dos pequenos produtores rurais. Revista Brasileira de Gestão e Desenvolvimento Regional, 4(1), 109-127. 